\title{
Response surface methodology approach for optimized compressive strength of some mix design concrete aggregates from waste cockle shells and glass powder
}

\author{
Sugito $^{a, b^{*}}$, Sofia W. Alisjahbana ${ }^{a, c}$ and Hery Riyanto ${ }^{b}$
}

${ }^{a}$ Department of Civil Engineering, Tarumanagara University, Jakarta 11440, Indonesia

${ }^{b}$ Department of Civil Engineering, Bandar Lampung University, Bandar Lampung 35142, Indonesia

${ }^{c}$ Department of Civil Engineering, Bakrie University, Jakarta 12940, Indonesia

\begin{tabular}{l}
\hline A R T I C L E I N F O \\
\hline Article history: \\
Received 4 December 2021 \\
Accepted 24 February 2022 \\
Available online \\
24 February 2022 \\
\hline Keywords: \\
Cockle shells powder \\
Compressive strength \\
Concrete \\
Epoxy resin \\
Glass powder \\
Waste
\end{tabular}
\begin{abstract}
A B S T R A C T
Nowadays, with increased demand for aggregates for concrete and an awareness of the need of protecting natural resources, experts are becoming increasingly interested in waste material as a building material substitute. However, the compressive strength is influenced by the composition of concrete. In this study, the compressive strength of concrete under substitution using waste from cockle shells and glass was investigated using Response Surface Methodology (RSM). Central Composite Design (CCD) based on RSM was used to assess the influence of epoxy resin, cockle shells powder, and glass powder on compressive strength responses. RSM developed first-order and secondorder mathematical models with findings from experimental design. Analysis of variance was used to determine the correctness of CCD's mathematical models. Desirability analysis was then employed to optimize epoxy resin, cockle shells powder, and glass powder yielding maximum compressive strength. The RSM analysis revealed that the empirical results fit well into linear and quadratic models of concrete compressive strength. The mixing components will produce cement with compressive strength in each formulation of $54.71 \mathrm{MPa}$ (4.88\% epoxy resin and $4.0 \%$ cockle shells powder), 47.82 $\mathrm{MPa}(6.85 \%$ epoxy resin and $8.0 \%$ glass powder), $147.0 \mathrm{MPa}$, (4\% cockle shells powder and $8 \%$ glass powder), and $56.08 \mathrm{MPa}$ ( $4.4 \%$ epoxy resin, $4.0 \%$ cockle shells powder, and $8.0 \%$ glass powder). The results confirmed that a reasonable compressive strength of concrete could be achieved using epoxy resin, cockle shells powder, and glass powder.
\end{abstract}

(C) 2022 Growing Science Ltd. All rights reserved.

\section{Introduction}

Today, eco-friendly construction approaches are growing rapidly. Utilizing materials derived from natural sources is one method of implementing the green construction idea. Regarding this approach, a study was conducted to investigate the potential of waste from cockle shells and glass as a material for partial cement replacement or filler material (Raseela and George, 2019). However, using this material in a concrete mix must still consider its compressive strength to maintain its safety.

Compressive strength should be optimized to maximize material waste from cockle shells and glass into concrete (Mohamad et al., 2021). This is frequently accomplished through single-factor optimization, in which all possible combinations of variables are tried. Thus it requires a long time involving a large number of experiments. Planning to optimize the compressive strength of concrete mixed with waste from cockle shells and glass is important to be done properly to avoid over or under design (Jayanti et al., 2021; Sitorus et al., 2018). Nevertheless, response surface methodology (RSM) is employed as an option to optimize the compressive strength of concrete. The key objective of RSM is to uncover and detect

* Corresponding author.

E-mail addresses: sugito@ubl.ac.id (Sugito) 
the interplay between optimal parameters and statistical model development. RSM in optimization reduces the number of experiments and saves time, space, and raw materials.

RSM has been widely used for concrete optimization compressive strength of different products from various material including waste from cockle shells (Murugan et al., 2020), palm shells (Basri et al., 1999), coconut shells (Gupta et al., 2020), walnut shells (Hilal et al., 2021), plastic waste and periwinkle shells (Ede et al., 2021). Moreover, many studies have used RSM to optimize the compressive strength of concrete aggregates from much substitution material (Habibi et al., 2021; Hammoudi et al., 2019; Nematzadeh et al., 2020). This indicated that optimization of compressive strength using RSM should be employed from substitution material.

RSM is becoming prominent in research for the optimality of various procedures, including the manufacture of concrete. Software tools used in the design of experiments using RSM include Design Expert and Minitab (Habibi et al., 2021; Hammoudi et al., 2019; Nematzadeh et al., 2020). These software tools provide optimal experimental designs, regression analyses, and suitable statistical tests. RSM as a partial factorial design has been shown to minimize the number of trials required compared to the use of complete factorial design. Additionally, it is well recognized that experimenters often lack the resources and time necessary to perform complete factorial studies and hence resort to frequently utilized partial factorial designs. One may conclude that RSM results in significant cost reductions in effort, time, and money.

This research captures the compressive strength of concrete containing waste from cockle shells and glass. The unique contribution of this research is on optimization of cockle shells powder and glass powder contents establishing maximum compressive strength of concrete. The applicability of this research is demonstrated through increased compressive strength due to the inclusion of cockle shells powder and glass powder in concrete. Hence, it highlights the potential compressive strength benefits of concrete incorporated with waste from cockle shells and glass, which can encourage corporations to adopt these sustainable construction materials.

\section{Materials and method}

\subsection{Experimental results}

This study utilized the class 3 design developed by the British Research Establishment (BRE). CCD of the response surface approach was used to generate 28 experimental runs. This number of runs reflects precise optimal values and illustrative experimental data. Three designs with different levels of epoxy resin, waste cockle shells, waste glass. Waste cockle shells and waste glass are crushed into powder before mixed with cement. The physical properties of cockle shells powder and glass powder are shown in Table 1. The epoxy resin has two-level including 0 and $13 \%$. Cockle shell powder is made with levels of $0,0.75,1,1.5,2,2.53$ and $4 \%$. Glass powder is made with levels of $0.75,1,1.5,2,2.5,3,3.5,4,6$, and $8 \%$. The independent variables consisting of epoxy resin, cockle shells powder, and glass powder were introduced in the design and were represented in a coded form as A (epoxy resin), B (cockle shells powder), and C (glass powder). Responses indicated as R1 defined the compressive strength of concrete.

Table 1. Properties material of fine aggregate for concrete

\begin{tabular}{lccc}
\hline \multicolumn{1}{c}{ Properties } & \multicolumn{2}{c}{ Material type } & \multirow{2}{*}{ Unit } \\
\cline { 2 - 3 } & Cockle shells powder & Glass powder & - \\
\hline Bulk specific gravity & $2.83 \pm 0.0375$ & $2.48 \pm 0.0028$ & - \\
Bulk SSD specific gravity & $2.84 \pm 0.0255$ & $2.50 \pm 0.0007$ & - \\
Apparent specific gravity & $2.86 \pm 0.0028$ & $2.54 \pm 0.0064$ & - \\
Absorption & $0.30 \pm 0.4271$ & $0.91 \pm 0.1442$ & $\%$ \\
\hline
\end{tabular}

\subsection{Experimental procedure}

The experimental design for all runs was rendered using Design Expert v.12 (Trial Version). The concrete casting including waste materials (cockle shells and glass), was conducted using manual mixing. A mixing procedure has been undertaken for about 8 minutes to ensure the concrete matrix's homogeneity. Fresh concrete was placed in lubricated molds following the blending of all the constituent materials. After that, fresh concrete was compacted utilizing a poker vibrator until uniform compaction was achieved. The specimens were then left for $24 \mathrm{~h}$ before demolding with cylindrical molded concrete (diameter of $80 \mathrm{~mm}$ and height of $160 \mathrm{~mm}$ ). After demolding, all specimens were measured using UTM.

\subsection{Measurement of compressive strength}

Compressive strengths measurements were conducted on $80 \times 160 \mathrm{~mm}$ (diameter $\times$ height) cylindrical specimens following ASTM C109-11. After 7 days of cure, testing was undertaken. The compressive strength test was conducted using a $250 \mathrm{kN}$ UTM RTF $1350,0.5 \mathrm{kN} / \mathrm{s}$. The specimens are placed between the lower plates of the UTM centrically (Fig. 1). Loading is carried out at a speed of $4-6 \mathrm{~kg} / \mathrm{cm}^{2}$ per second. 


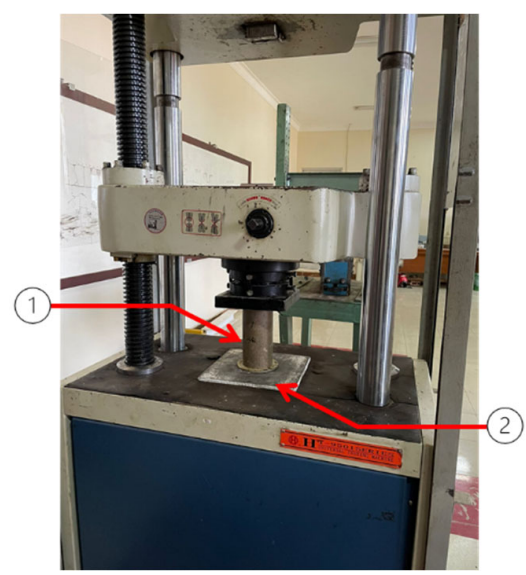

Fig. 1. Set-up for compressive strength tests (1-specimens, 2-lower plates )

\subsection{Optimization by RSM}

Response surface methodology (RSM) forecasted the impact, cockle shells powder, and glass powder as independent variables on compressive strength responses. It covered the optimization aspect by obtaining the optimum of compressive strength. RSM analysis may be used to determine the linear interaction and quadratic effect of independent factors on the concrete characteristics. The study optimized the combined effects of these variables in order to reduce or maximize desired results.

Data analysis will be carried out using statistical Analysis of variance (ANOVA). Data analysis was performed on compressive strength response. The reading results using ANOVA analysis include the significance of the P-value on the model, lack of fit, the difference between the R-squared adj value and the R-squared pred value, and adequate precision. After the overall response is analyzed, the compressive strength is optimized based on the factors and responses determined. Optimization is done by determining the priority scale of each factor and response. The optimization obtained is then reverified whether it follows what has been predicted by the software so that it can be applied and increase the compressive strength of concrete.

The optimization approach was designed to find the optimal values for three independent factors that provide desirable response variables. Response models visualization using graphical optimization led to understanding the influence of epoxy resin, cockle shells powder, and glass powder on concrete compressive strength. Numerical optimization's overall objective was to maximize compressive strength. Multiple optimization approaches, such as desirability analysis, were used to integrate these objectives. This method aimed to optimize compressive strength to get feasible parameters of epoxy resin, cockle shells powder, and glass powder.

\section{Results and discussion}

\subsection{Regression and establishment}

The influence of independent parameters (epoxy resin, waste of cockle shells, waste of glass) on the compressive strength performance of concrete was evaluated. Both response variables were predicted using polynomial coefficient computations using experimental data. The ANOVA results indicated that linear and quadratic models might represent compressive strength. Eq. (1) to Eq. (4) depict the regression equations created for each response using the response surface approach.

$$
\begin{aligned}
& \mathrm{Cs} 1=53.74+24.43 \mathrm{~A}+7.05 \mathrm{~B}, \\
& \mathrm{Cs} 2=49.85+24.98 \mathrm{~A}-3.37 \mathrm{C}, \\
& \mathrm{Cs} 3=84.86+26.16 \mathrm{~B}+33.47 \mathrm{C}+14.51 \mathrm{BC}+14.87 \mathrm{~B}^{2}-26.87 \mathrm{C}^{2}, \\
& \mathrm{Cs} 4=54.73+24.18 \mathrm{~A}+7.58 \mathrm{~B}+1.57 \mathrm{C},
\end{aligned}
$$

where A, B, and C are epoxy resin $(\%, w / w)$, cockle shells powder $(\%, w / w)$, and glass powder $(\%$, w/w), respectively, and Cs1, Cs2, Cs3, Cs4 predict compressive strength for each mixing of concrete. A positive variable in a regression equation suggests a synergistic effect, in which the outcome increases as the independent variables' inputs increase. On another side, a negative sign indicates an antagonistic impact, in which the response rises as the input variables are decreased. A total of 28 experiments were completed to optimize the three parameters (epoxy resin, waste of cockle shells, waste of glass), and more 4 replicated each combination parameter using RSM. The load-displacement data from UTM is shown in Fig. 2. The results show that the maximum compressive strength of concrete obtained was $87.11 \mathrm{MPa}$ (at load $437.82 \mathrm{KN}$ ) using the epoxy resin 
of $13 \%(\mathrm{w} / \mathrm{w})$, cockle shells powder of $3 \%(\mathrm{w} / \mathrm{w})$, and glass powder of $2 \%(\mathrm{w} / \mathrm{w})$, while the minimum compressive strength of concrete obtained was $24.17 \mathrm{MPa}$ (at load $121.80 \mathrm{KN}$ ) using the epoxy resin of $0 \%(\mathrm{w} / \mathrm{w})$, cockle shells powder of $1 \%$ $(\mathrm{w} / \mathrm{w})$, and glass powder of $3 \%(\mathrm{w} / \mathrm{w})$. A quadratic model (Eq. (1) to Eq. (4)) was developed via multiple nonlinear regression of the empirical data to forecast the compressive strength of concrete.

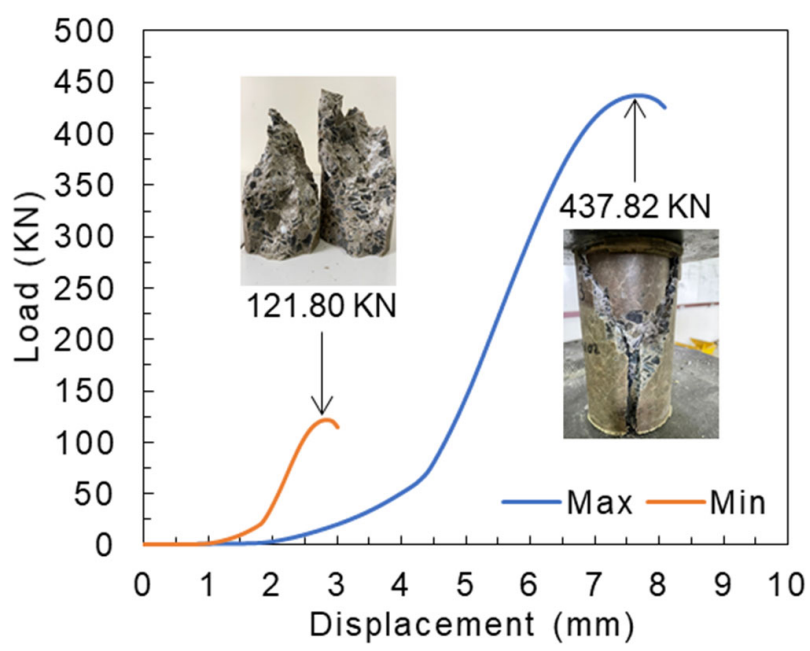

Fig. 2. Load-displacement data from UTM on min and max compressive strength of concrete

\subsection{Analysis of compressive strength of concrete response}

\subsubsection{Effect of factors epoxy resin and cockle shells powder}

Table 2 establishes the model of compressive strength of concrete by ANOVA under the effect of epoxy resin and cockle shells powder. The interaction influence of epoxy resin and cockle shells powder on the compressive strength of concrete is shown in Fig. 3. The three-dimensional surface graph relates to the linear model compressive strength response. The normal probability and residual vs. predicted (fits) plots are shown in Fig. 4. The result of the compressive strength of the concrete response is displayed in Table 3. According to Table 3, despite a small difference for one DFFITS value, the model is usually regarded as acceptable.

Table 2. ANOVA for compressive strength of concrete response surface model under the effect of epoxy resin and cockle shells powder

\begin{tabular}{lcccccc}
\hline \multicolumn{1}{c}{ Source } & Sum of squares & df & Mean square & F-value & p-value & Significant \\
\hline Model & 16764.17 & 2 & 8382.09 & 265.14 & $<0.0001$ & \\
A-Epoxy resin & 16368.58 & 1 & 16368.58 & 517.77 & $<0.0001$ & \\
B-Rotational speed & 370.56 & 1 & 370.56 & 11.72 & 0.0021 & \\
Residual & 790.34 & 25 & 31.61 & & & Not significant \\
Lack of fit & 308.89 & 11 & 28.08 & 0.8166 & 0.6270 & \\
Pure error & 481.45 & 14 & 34.39 & & & \\
\hline Total & 17554.51 & 27 & & & & \\
\hline
\end{tabular}

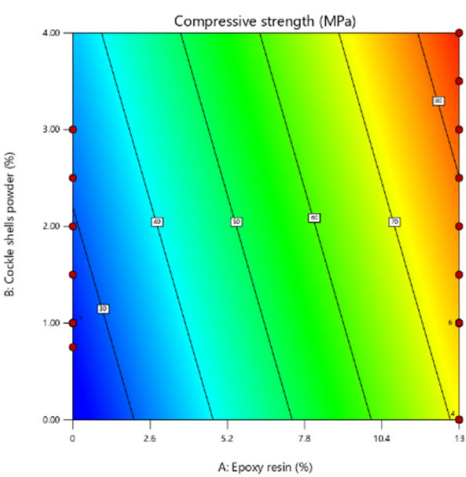

(a) Contour plot

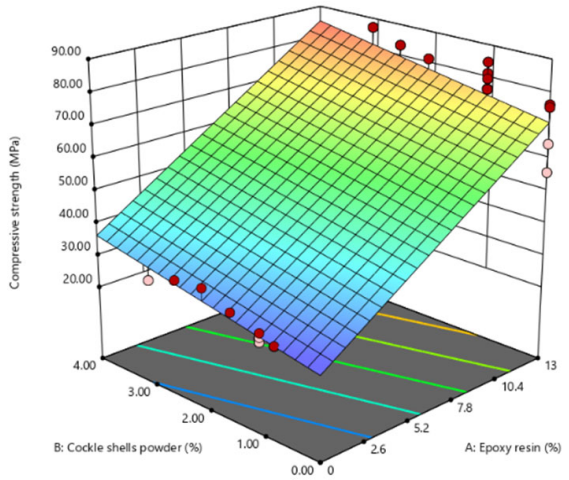

(b) 3-D response surface plot

Fig. 3. Contour plot and response surface plot of concrete compressive strength under the effect of epoxy resin and cockle shells powder 
A statistical test was run on the regression model and individual model variables to determine the effect of epoxy resin and cockle shells powder on the compressive strength of concrete. Table 2 shows the ANOVA for the data yielded by Equation 1 for compressive strength of concrete under the effect of epoxy resin and cockle shells powder. A high F-value and a low Pvalue demonstrate the significance of the developed model (Hamouda et al., 2015; Yirgu et al., 2021). The F-value of 265.14 and P-value of 0.0001 in this study showed that the model was significant. All linear models had significant impacts on the compressive strength of concrete. The F-value and P-value for lack of fit were 0.8166 and 0.6270 , respectively, indicating that the lack of fit was not statistically significant compared to the error and that the model fit is satisfactory (Karri et al., 2021).

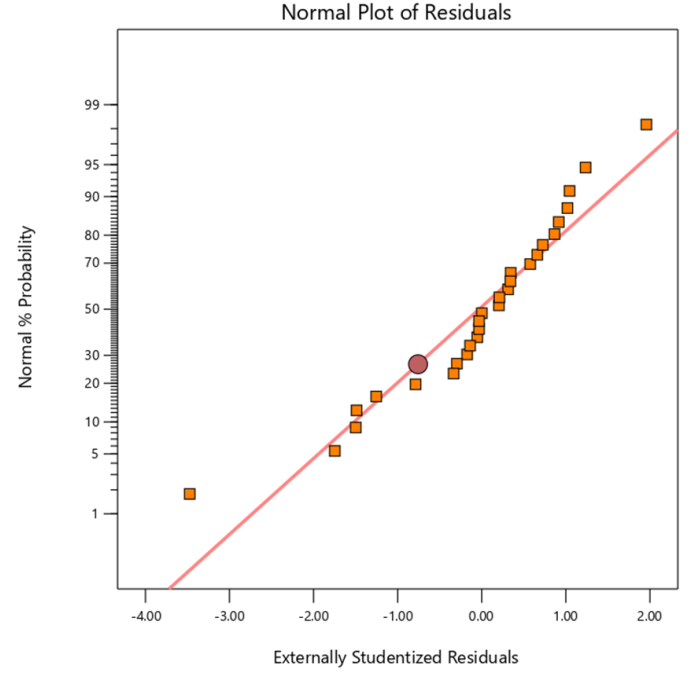

(a) Normal probability plot

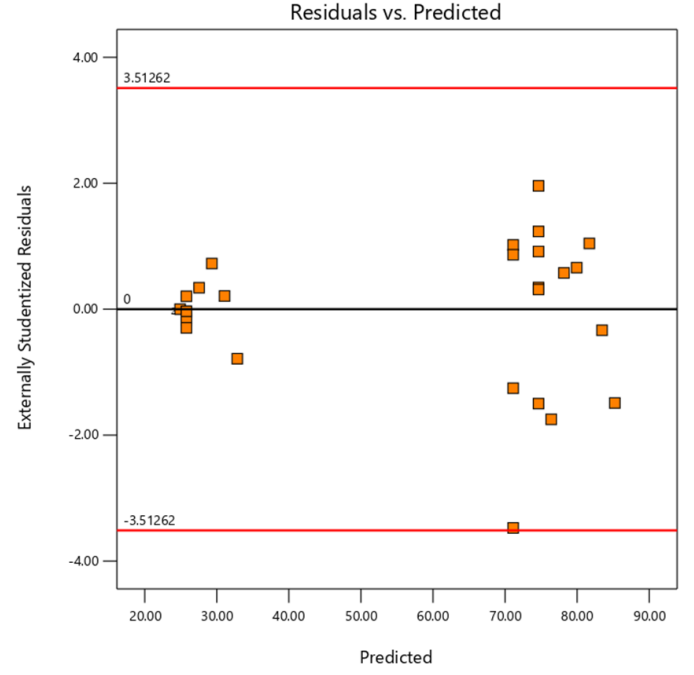

(b) Residual vs predicted (fits) plot

Fig. 4. Diagnostic plots for compressive strength of concrete under the effect of epoxy resin and cockle shells powder

Table 3. Report of diagnostic case for compressive strength of concrete under the effect of epoxy resin and cockle shells powder

\begin{tabular}{|c|c|c|c|c|c|c|c|c|c|}
\hline $\begin{array}{l}\text { Run } \\
\text { Order }\end{array}$ & $\begin{array}{c}\text { Actual } \\
\text { Value }\end{array}$ & $\begin{array}{l}\text { Predicted } \\
\text { Value }\end{array}$ & Residual & Leverage & $\begin{array}{l}\text { Internally } \\
\text { Studentized } \\
\text { Residuals }\end{array}$ & $\begin{array}{c}\text { Externally } \\
\text { Studentized } \\
\text { Residuals }\end{array}$ & $\begin{array}{c}\text { Cook's } \\
\text { Distance }\end{array}$ & $\begin{array}{c}\text { Influence } \\
\text { on Fitted } \\
\text { Value } \\
\text { DFFITS } \\
\end{array}$ & $\begin{array}{c}\text { Standard } \\
\text { Order }\end{array}$ \\
\hline 1 & 24.84 & 25.79 & -0.9488 & 0.089 & -0.177 & -0.173 & 0.001 & -0.054 & 1 \\
\hline 2 & 25.49 & 25.79 & -0.2928 & 0.089 & -0.055 & -0.053 & 0.000 & -0.017 & 2 \\
\hline 3 & 26.91 & 25.79 & 1.12 & 0.089 & 0.209 & 0.205 & 0.001 & 0.064 & 3 \\
\hline 4 & 25.61 & 25.79 & -0.1790 & 0.089 & -0.033 & -0.033 & 0.000 & -0.010 & 4 \\
\hline 5 & 25.03 & 25.79 & -0.7595 & 0.089 & -0.142 & -0.139 & 0.001 & -0.043 & 5 \\
\hline 6 & 24.17 & 25.79 & -1.62 & 0.089 & -0.301 & -0.296 & 0.003 & -0.092 & 6 \\
\hline 7 & 55.94 & 71.12 & -15.18 & 0.129 & -2.892 & -3.473 & 0.412 & $-1.336^{(1)}$ & 7 \\
\hline 8 & 76.47 & 71.12 & 5.35 & 0.129 & 1.019 & 1.020 & 0.051 & 0.392 & 8 \\
\hline 9 & 75.68 & 71.12 & 4.56 & 0.129 & 0.870 & 0.865 & 0.037 & 0.333 & 9 \\
\hline 10 & 64.61 & 71.12 & -6.51 & 0.129 & -1.241 & -1.255 & 0.076 & -0.483 & 10 \\
\hline 11 & 67.26 & 76.41 & -9.15 & 0.063 & -1.680 & -1.748 & 0.063 & -0.453 & 11 \\
\hline 12 & 81.33 & 78.17 & 3.16 & 0.074 & 0.584 & 0.576 & 0.009 & 0.163 & 12 \\
\hline 13 & 83.49 & 79.94 & 3.56 & 0.103 & 0.668 & 0.660 & 0.017 & 0.223 & 13 \\
\hline 14 & 87.11 & 81.70 & 5.41 & 0.148 & 1.043 & 1.045 & 0.063 & 0.435 & 14 \\
\hline 15 & 81.76 & 83.46 & -1.70 & 0.210 & -0.340 & -0.334 & 0.010 & -0.172 & 15 \\
\hline 16 & 78.33 & 85.23 & -6.90 & $0.288^{(2)}$ & -1.454 & -1.489 & 0.285 & -0.948 & 16 \\
\hline 17 & 66.71 & 74.65 & -7.94 & 0.068 & -1.463 & -1.499 & 0.052 & -0.405 & 17 \\
\hline 18 & 76.55 & 74.65 & 1.90 & 0.068 & 0.351 & 0.344 & 0.003 & 0.093 & 18 \\
\hline 19 & 81.28 & 74.65 & 6.63 & 0.068 & 1.222 & 1.235 & 0.036 & 0.334 & 19 \\
\hline 20 & 84.72 & 74.65 & 10.07 & 0.068 & 1.856 & 1.958 & 0.084 & 0.529 & 20 \\
\hline 21 & 79.63 & 74.65 & 4.99 & 0.068 & 0.919 & 0.916 & 0.021 & 0.248 & 21 \\
\hline 22 & 76.37 & 74.65 & 1.73 & 0.068 & 0.319 & 0.313 & 0.002 & 0.085 & 22 \\
\hline 23 & 24.91 & 24.91 & 0.0035 & 0.097 & 0.001 & 0.001 & 0.000 & 0.000 & 23 \\
\hline 24 & 25.61 & 25.79 & -0.1790 & 0.089 & -0.033 & -0.033 & 0.000 & -0.010 & 24 \\
\hline 25 & 29.42 & 27.55 & 1.87 & 0.084 & 0.347 & 0.341 & 0.004 & 0.103 & 25 \\
\hline 26 & 33.23 & 29.31 & 3.92 & 0.096 & 0.733 & 0.726 & 0.019 & 0.236 & 26 \\
\hline 27 & 32.20 & 31.08 & 1.12 & 0.124 & 0.214 & 0.209 & 0.002 & 0.079 & 27 \\
\hline 28 & 28.78 & 32.84 & -4.06 & 0.170 & -0.793 & -0.787 & 0.043 & -0.356 & 28 \\
\hline
\end{tabular}

(1) Exceeds limits.

(2) Observation with leverage $>2.00 \times$ (average leverage). 
ANOVA was used to determine the model's satisfactoriness under the effect of epoxy resin and cockle shells powder. $\mathrm{R}^{2}$ and adjusted $\mathrm{R}^{2}$ values of 0.955 and 0.9514 indicate a high degree of congruence between experimental results and fitted regression models. The greater $\mathrm{R}^{2}$ indicated that the model was very reliable in predicting the compressive strength of concrete; the adjusted $\mathrm{R}^{2}$ indicated the amount of variation around the mean explained by the model. The high adjusted $\mathrm{R}^{2}$ value indicated an acceptable agreement between observed and anticipated compressive strength values for concrete, implying that the proposed linear model equation produces satisfactory and accurate results. The lack of fit is also significant under the effect of epoxy resin and cockle shells powder, which is expected because an appropriate model is required (Sinkhonde et al., 2021). The distribution of points compatible with the regression line demonstrates the applied regression model's increased adequacy (Salarian et al., 2016). Also, random bouncing of residuals presents that the implied relationship is good. Simultaneously, the model's low coefficient of variance $(10.20 \%)$ suggested a high degree of accuracy and a high degree of dependability for the observed data (Ren et al., 2017). Hence, the generated model was satisfactory for estimating the compressive strength of concrete in the range of experimental variables under the effect of epoxy resin and cockle shells powder.

\subsubsection{Effect of factors epoxy resin and glass powder}

Table 4 establishes the model of compressive strength of concrete by ANOVA under the effect of epoxy resin and glass powder. The interaction influence of epoxy resin and glass powder on the compressive strength of concrete is shown in Fig. 5. The three-dimensional surface graph relates to the linear model compressive strength response. The normal probability and residual vs. predicted (fits) plots are shown in Fig. 6. The result of the compressive strength of the concrete response is displayed in Table 5. According to Table 5, despite a small difference for one Cook's Distance values and two DFFITS values, the model is usually regarded as acceptable.

Table 4. ANOVA for compressive strength of concrete response surface model under the effect of epoxy resin and glass powder

\begin{tabular}{lccccc}
\hline \multicolumn{1}{c}{ Source } & Sum of squares & df & Mean square & F-value & p-value \\
\hline Model & 16437.42 & 2 & 8218.71 & 183.93 & $<0.0001$ \\
A-Epoxy resin & 14567.55 & 1 & 14567.55 & 326.01 & $<0.0001$ \\
C-Glass powder & 43.81 & 1 & 43.81 & 0.9804 & 0.3316 \\
Residual & 1117.09 & 25 & 44.68 & & 0.5258 \\
Lack of fit & 326.60 & 11 & 29.69 & & 0.8554 \\
Pure error & 790.49 & 14 & 56.46 & & not significant \\
\hline Total & 17554.51 & 27 & & & \\
\hline
\end{tabular}

A statistical test was run on the regression model and individual model variables to determine the effect of epoxy resin and glass powder on the compressive strength of concrete. Table 4 presents the ANOVA for the data yielded by Eq. (2) for the compressive strength of concrete under the effect of epoxy resin and glass powder. F-value of 183.93 and P-value of 0.0001 in this study showed that the model was significant. All linear models had significant impacts on the compressive strength of concrete. The F-value and the P-value for lack of fit were 0.5258 and 0.8554 , indicating that the lack of fit was not statistically significant compared to the error and that the model fit is satisfactory.

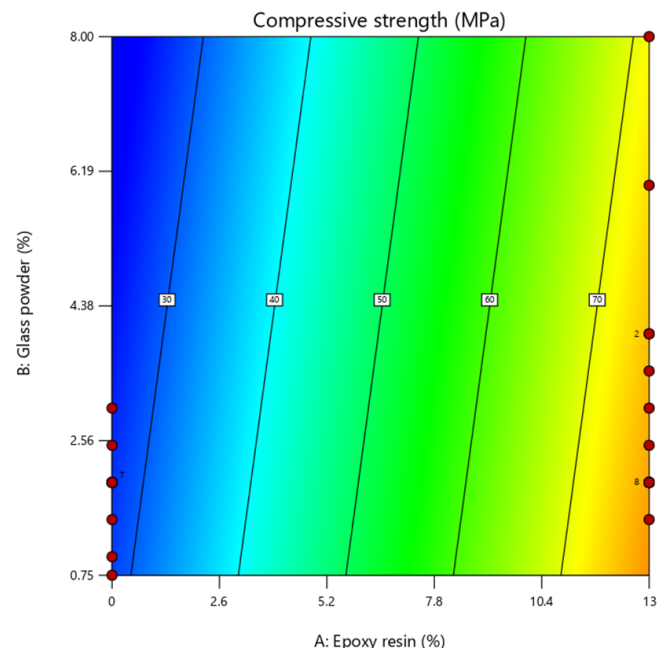

(a) Contour plot

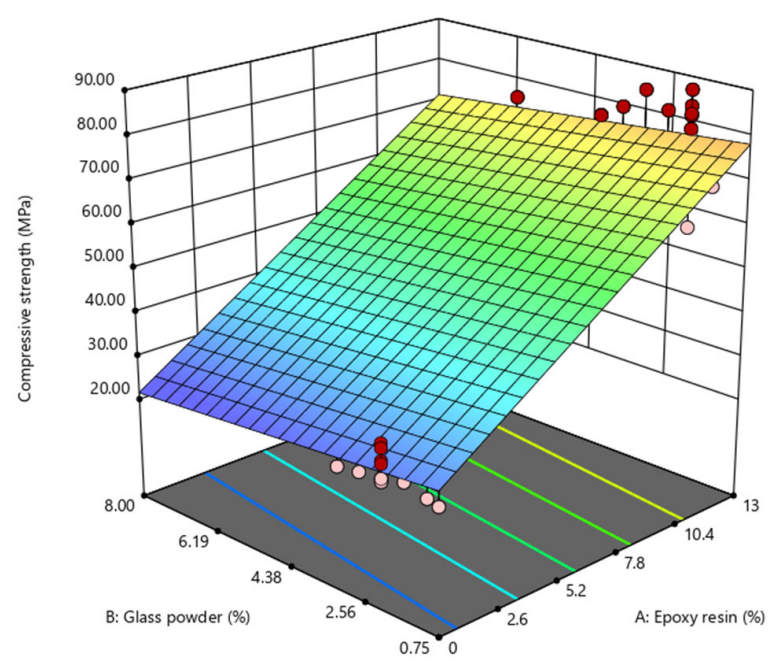

(b) 3-D response surface plot

Fig. 5. Contour plot and response surface plot of concrete compressive strength under the effect of epoxy resin and glass powder 


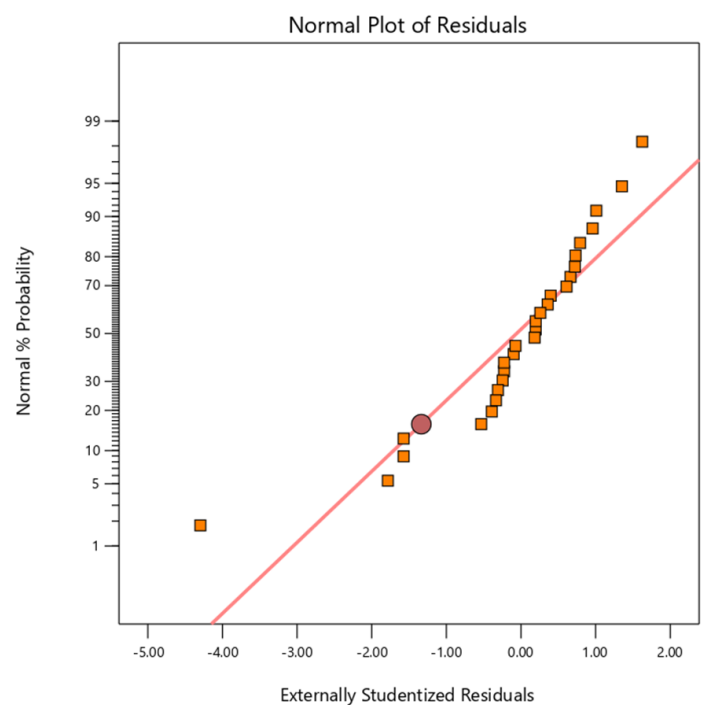

(a) Normal probability plot

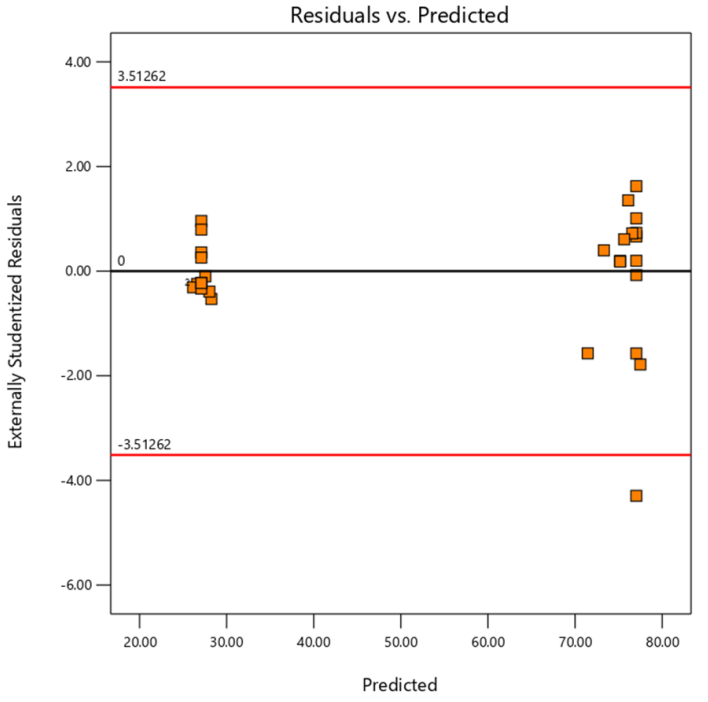

(b) Residual vs predicted (fits) plot

Fig. 6. Diagnostic plots response for compressive strength of concrete under the effect of epoxy resin and glass powder

Table 5. Report of diagnostic case for compressive strength of concrete under the effect of epoxy resin and glass powder

\begin{tabular}{|c|c|c|c|c|c|c|c|c|c|}
\hline $\begin{array}{l}\text { Run } \\
\text { Order }\end{array}$ & $\begin{array}{c}\text { Actual } \\
\text { Value }\end{array}$ & $\begin{array}{c}\text { Predicted } \\
\text { Value }\end{array}$ & Residual & Leverage & $\begin{array}{c}\text { Internally } \\
\text { Studentized } \\
\text { Residuals }\end{array}$ & $\begin{array}{c}\text { Externally } \\
\text { Studentized } \\
\text { Residuals }\end{array}$ & $\begin{array}{c}\text { Cook's } \\
\text { Distance }\end{array}$ & $\begin{array}{c}\text { Influence } \\
\text { on Fitted } \\
\text { Value } \\
\text { DFFITS }\end{array}$ & $\begin{array}{c}\text { Standard } \\
\text { Order }\end{array}$ \\
\hline 1 & 24.84 & 28.25 & -3.41 & 0.109 & -0.541 & -0.533 & 0.012 & -0.187 & 1 \\
\hline 2 & 25.49 & 28.02 & -2.52 & 0.099 & -0.397 & -0.391 & 0.006 & -0.130 & 2 \\
\hline 3 & 26.91 & 27.55 & -0.6427 & 0.086 & -0.101 & -0.099 & 0.000 & -0.030 & 3 \\
\hline 4 & 25.61 & 27.09 & -1.48 & 0.084 & -0.231 & -0.227 & 0.002 & -0.068 & 4 \\
\hline 5 & 25.03 & 26.62 & -1.59 & 0.091 & -0.250 & -0.245 & 0.002 & -0.077 & 5 \\
\hline 6 & 24.17 & 26.16 & -1.99 & 0.107 & -0.314 & -0.309 & 0.004 & -0.107 & 6 \\
\hline 7 & 55.94 & 77.04 & -21.09 & 0.083 & -3.296 & $-4.295^{(1)}$ & 0.330 & $-1.296^{(2)}$ & 7 \\
\hline 8 & 76.47 & 75.18 & 1.29 & 0.081 & 0.201 & 0.198 & 0.001 & 0.059 & 8 \\
\hline 9 & 75.68 & 73.32 & 2.36 & $0.236^{(3)}$ & 0.405 & 0.398 & 0.017 & 0.221 & 9 \\
\hline 10 & 64.61 & 71.46 & -6.85 & $0.550^{(3)}$ & -1.527 & -1.572 & $0.950^{(2)}$ & $-1.737^{(2)}$ & 10 \\
\hline 11 & 67.26 & 77.04 & -9.78 & 0.083 & -1.528 & -1.572 & 0.071 & -0.474 & 11 \\
\hline 12 & 81.33 & 77.04 & 4.30 & 0.083 & 0.671 & 0.664 & 0.014 & 0.200 & 12 \\
\hline 13 & 83.49 & 77.04 & 6.46 & 0.083 & 1.009 & 1.009 & 0.031 & 0.305 & 13 \\
\hline 14 & 87.11 & 77.04 & 10.08 & 0.083 & 1.575 & 1.625 & 0.075 & 0.491 & 14 \\
\hline 15 & 81.76 & 77.04 & 4.72 & 0.083 & 0.738 & 0.731 & 0.017 & 0.221 & 15 \\
\hline 16 & 78.33 & 77.04 & 1.29 & 0.083 & 0.202 & 0.198 & 0.001 & 0.060 & 16 \\
\hline 17 & 66.71 & 77.50 & -10.80 & 0.109 & -1.711 & -1.784 & 0.119 & -0.623 & 17 \\
\hline 18 & 76.55 & 77.04 & -0.4886 & 0.083 & -0.076 & -0.075 & 0.000 & -0.023 & 18 \\
\hline 19 & 81.28 & 76.57 & 4.71 & 0.068 & 0.729 & 0.722 & 0.013 & 0.195 & 19 \\
\hline 20 & 84.72 & 76.11 & 8.61 & 0.063 & 1.331 & 1.353 & 0.039 & 0.349 & 20 \\
\hline 21 & 79.63 & 75.64 & 3.99 & 0.067 & 0.618 & 0.610 & 0.009 & 0.163 & 21 \\
\hline 22 & 76.37 & 75.18 & 1.20 & 0.081 & 0.187 & 0.183 & 0.001 & 0.054 & 22 \\
\hline 23 & 24.91 & 27.09 & -2.18 & 0.084 & -0.340 & -0.334 & 0.004 & -0.101 & 23 \\
\hline 24 & 25.61 & 27.09 & -1.48 & 0.084 & -0.231 & -0.227 & 0.002 & -0.068 & 24 \\
\hline 25 & 29.42 & 27.09 & 2.33 & 0.084 & 0.365 & 0.358 & 0.004 & 0.108 & 25 \\
\hline 26 & 33.23 & 27.09 & 6.15 & 0.084 & 0.960 & 0.959 & 0.028 & 0.290 & 26 \\
\hline 27 & 32.20 & 27.09 & 5.11 & 0.084 & 0.799 & 0.793 & 0.019 & 0.240 & 27 \\
\hline 28 & 28.78 & 27.09 & 1.69 & 0.084 & 0.265 & 0.260 & 0.002 & 0.078 & 28 \\
\hline
\end{tabular}

(1) Observation with External Stud. Residuals > 3.51

(2) Exceeds limits

(3) Observation with leverage $>2.00 \times$ (average leverage).

The greater $\mathrm{R}^{2}$ value indicated that the model was very reliable in predicting the compressive strength of concrete; the adjusted $\mathrm{R}^{2}$ value indicated the amount of variation around the mean explained by the model. The $\mathrm{R}^{2}$-value showed $93.64 \%$ of the variability in compressive strength of concrete defined by the linear model in this investigation. The high adjusted R2 value indicated an acceptable agreement between observed and forecasted compressive strength values for concrete, indicating that the proposed linear model equation produces satisfactory and accurate results. The Adj $\mathrm{R}^{2}(0.9313)$ and pred $\mathrm{R}^{2}(0.9364)$ in this treatment have a difference of less than 0.2, indicating that they are in proper agreement with each other. Simultaneously, the model's low coefficient of variance (12.13\%) suggested a high degree of accuracy and a high degree of dependability for the observed data. Hence, the generated model was satisfactory for estimating the compressive strength of concrete in the range of experimental variables under the effect of epoxy resin and glass powder. 


\subsubsection{Effect of factors cockle shells powder and glass powder}

Table 6 establishes the model of compressive strength of concrete by ANOVA under the effect of cockle shells powder and glass powder. The interaction influence of cockle shells powder and glass powder on the compressive strength of concrete is shown in Fig. 7. The three-dimensional surface graph relates to the quadratic model compressive strength response. The normal probability and residual vs. predicted (fits) plots are shown in Figure 8. The result of the compressive strength of the concrete response is displayed in Table 7.

Table 6. ANOVA for compressive strength of concrete response surface model under the effect of cockle shells powder and glass powder

\begin{tabular}{|c|c|c|c|c|c|c|}
\hline Source & Sum of squares & df & Mean square & F-value & p-value & \\
\hline Model & 5439.24 & 5 & 1087.85 & 1.98 & 0.1224 & Not significant \\
\hline B-Cockle shells powder & 85.17 & 1 & 85.17 & 0.1547 & 0.6979 & \\
\hline C-Glass powder & 71.60 & 1 & 71.60 & 0.1300 & 0.7218 & \\
\hline $\mathrm{AB}$ & 11.03 & 1 & 11.03 & 0.0200 & 0.8887 & \\
\hline $\mathrm{A}^{2}$ & 335.20 & 1 & 335.20 & 0.6087 & 0.4436 & \\
\hline $\mathrm{B}^{2}$ & 383.80 & 1 & 383.80 & 0.6969 & 0.4128 & \\
\hline Residual & 12115.28 & 22 & 550.69 & & & \\
\hline Lack of fit & 1288.60 & 13 & 99.12 & 0.0824 & 0.9999 & Not significant \\
\hline Pure error & 10826.68 & 9 & 1202.96 & & & \\
\hline Total & 17554.51 & 27 & & & & \\
\hline
\end{tabular}

A statistical test was run on the regression model and individual model variables to determine the effect of cockle shells powder and glass powder on the compressive strength of concrete. Table 6 shows the ANOVA for the data yielded by Eq. (3) for the compressive strength of concrete under the effect of cockle shells powder and glass powder. The F-value of 1.98 and P-value of 0.1224 in this study showed that the model was not significant. All linear terms, two quadratic terms (A2, and B2), and interactive terms $(\mathrm{AB})$ had no significant effects on the compressive strength of concrete. The F-value and P-value for lack of fit were 0.0824 and 0.9999 , respectively, indicating that the lack of fit was not statistically significant in relation to the error and that the model fit is satisfactory.

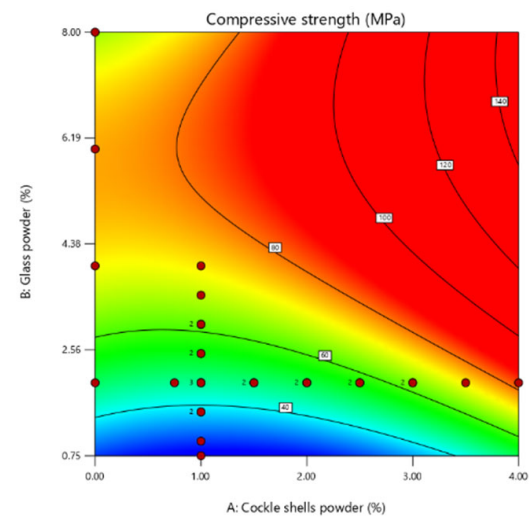

(a) Contour plot

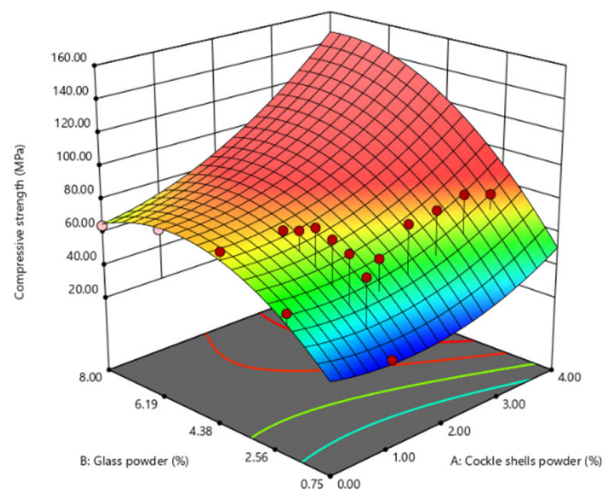

(b) 3-D response surface plot

Fig. 7. Contour plot and response surface plot of concrete compressive strength under the effect of cockle shells powder and glass powder

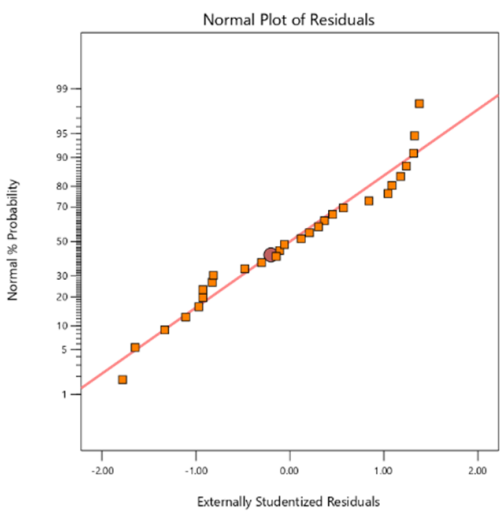

(a) Normal probability plot

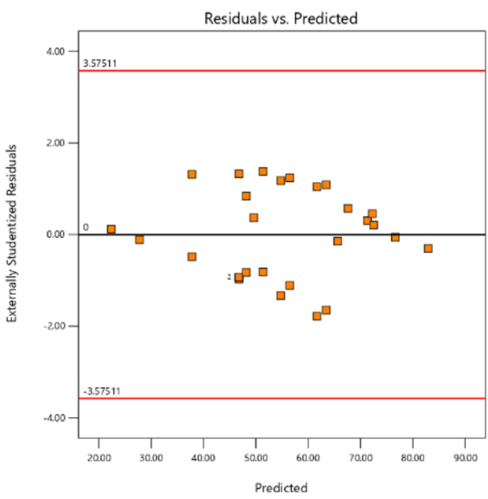

(b) Residual vs predicted (fits) plot

Fig. 8. Diagnostic plots response for compressive strength of concrete under the effect of cockle shells powder and glass powder 
Table 7. Report of diagnostic case for compressive strength of concrete under the effect of cockle shells powder and glass powder

\begin{tabular}{|c|c|c|c|c|c|c|c|c|c|}
\hline $\begin{array}{l}\text { Run } \\
\text { Order }\end{array}$ & $\begin{array}{c}\text { Actual } \\
\text { Value }\end{array}$ & $\begin{array}{c}\text { Predicted } \\
\text { Value }\end{array}$ & Residual & Leverage & $\begin{array}{c}\text { Internally } \\
\text { Studentized } \\
\text { Residuals }\end{array}$ & $\begin{array}{c}\text { Externally } \\
\text { Studentized } \\
\text { Residuals }\end{array}$ & $\begin{array}{c}\text { Cook's } \\
\text { Distance }\end{array}$ & $\begin{array}{c}\text { Influence } \\
\text { on Fitted } \\
\text { Value } \\
\text { DFFITS }\end{array}$ & $\begin{array}{c}\text { Standard } \\
\text { Order }\end{array}$ \\
\hline 1 & 24.84 & 22.42 & 2.42 & 0.298 & 0.123 & 0.120 & 0.001 & 0.078 & 1 \\
\hline 2 & 25.49 & 27.80 & -2.31 & 0.205 & -0.110 & -0.108 & 0.001 & -0.055 & 2 \\
\hline 3 & 26.91 & 37.81 & -10.90 & 0.095 & -0.488 & -0.480 & 0.004 & -0.156 & 3 \\
\hline 4 & 25.61 & 46.79 & -21.18 & 0.055 & -0.929 & -0.926 & 0.008 & -0.224 & 4 \\
\hline 5 & 25.03 & 54.75 & -29.72 & 0.063 & -1.309 & -1.331 & 0.019 & -0.345 & 5 \\
\hline 6 & 24.17 & 61.69 & -37.52 & 0.114 & -1.698 & -1.780 & 0.062 & -0.637 & 6 \\
\hline 7 & 55.94 & 49.62 & 6.33 & $0.485^{(1)}$ & 0.376 & 0.368 & 0.022 & 0.357 & 7 \\
\hline 8 & 76.47 & 71.32 & 5.15 & $0.505^{(1)}$ & 0.312 & 0.305 & 0.017 & 0.308 & 8 \\
\hline 9 & 75.68 & 76.67 & -0.9886 & $0.495^{(1)}$ & -0.059 & -0.058 & 0.001 & -0.057 & 9 \\
\hline 10 & 64.61 & 65.66 & -1.06 & $0.907^{(1)}$ & -0.148 & -0.144 & 0.036 & -0.451 & 10 \\
\hline 11 & 67.26 & 48.17 & 19.10 & 0.077 & 0.847 & 0.841 & 0.010 & 0.244 & 11 \\
\hline 12 & 81.33 & 51.40 & 29.93 & 0.109 & 1.352 & 1.379 & 0.037 & 0.483 & 12 \\
\hline 13 & 83.49 & 56.49 & 27.00 & 0.118 & 1.225 & 1.240 & 0.033 & 0.453 & 13 \\
\hline 14 & 87.11 & 63.45 & 23.67 & 0.131 & 1.082 & 1.086 & 0.029 & 0.421 & 14 \\
\hline 15 & 81.76 & 72.26 & 9.50 & 0.238 & 0.464 & 0.456 & 0.011 & 0.255 & 15 \\
\hline 16 & 78.33 & 82.93 & -4.60 & $0.593^{(1)}$ & -0.307 & -0.301 & 0.023 & -0.362 & 16 \\
\hline 17 & 66.71 & 37.81 & 28.90 & 0.095 & 1.295 & 1.316 & 0.029 & 0.427 & 17 \\
\hline 18 & 76.55 & 46.79 & 29.76 & 0.055 & 1.305 & 1.327 & 0.017 & 0.321 & 18 \\
\hline 19 & 81.28 & 54.75 & 26.53 & 0.063 & 1.168 & 1.178 & 0.015 & 0.306 & 19 \\
\hline 20 & 84.72 & 61.69 & 23.03 & 0.114 & 1.042 & 1.045 & 0.023 & 0.374 & 20 \\
\hline 21 & 79.63 & 67.60 & 12.03 & 0.217 & 0.579 & 0.570 & 0.016 & 0.300 & 21 \\
\hline 22 & 76.37 & 72.50 & 3.88 & 0.401 & 0.214 & 0.209 & 0.005 & 0.171 & 22 \\
\hline 23 & 24.91 & 46.80 & -21.89 & 0.075 & -0.970 & -0.969 & 0.013 & -0.276 & 23 \\
\hline 24 & 25.61 & 46.79 & -21.18 & 0.055 & -0.929 & -0.926 & 0.008 & -0.224 & 24 \\
\hline 25 & 29.42 & 48.17 & -18.75 & 0.077 & -0.832 & -0.826 & 0.010 & -0.239 & 25 \\
\hline 26 & 33.23 & 51.40 & -18.17 & 0.109 & -0.820 & -0.814 & 0.014 & -0.285 & 26 \\
\hline 27 & 32.20 & 56.49 & -24.29 & 0.118 & -1.102 & -1.108 & 0.027 & -0.405 & 27 \\
\hline
\end{tabular}

(1) Observation with leverage $>2.00 \times$ (average leverage).

ANOVA evaluated the satisfactoriness of the model under the effect of cockle shells powder and glass powder. $\mathrm{R}^{2}$ and adjusted $\mathrm{R}^{2}$ values of 0.3098 and 0.1530 indicated weak relativity of experimental findings with the fitted regression model. The small of $\mathrm{R}^{2}$ indicated low reliability of the model in predicting compressive strength of concrete; the adjusted $\mathrm{R}^{2}$ measured the amount of variation about a mean explained by the model. The $\mathrm{R}^{2}$-value indicated $30.98 \%$ of the variability in compressive strength of concrete explained by the quadratic model in this study. The model's high coefficient of variance (42.57\%) suggested a low degree of accuracy and a high degree of dependability for the observed data. Hence, the developed model was fair for predicting the compressive strength of concrete in the range of experimental variables under the effect of cockle shells powder and glass powder.

\subsubsection{Effect of factors epoxy resin, cockle shells powder and glass powder}

Table 8 establishes the model of compressive strength of concrete by ANOVA under the effect of epoxy resin, cockle shells powder and glass powder. The interaction influence of epoxy resin, cockle shells powder, and glass powder on the compressive strength of concrete is shown in Fig. 9. The three-dimensional surface graph relates to the linear model compressive strength response. The normal probability and residual vs. predicted (fits) plots are shown in Fig. 10. The result of the compressive strength of the concrete response is displayed in Table 9. According to Table 9, despite a small difference for one Cook's Distance values and two DFFITS values, the model is usually regarded as acceptable.

Table 8. ANOVA for compressive strength of concrete response surface model under the effect of epoxy resin, cockle shells powder and glass powder

\begin{tabular}{|c|c|c|c|c|c|c|}
\hline Source & Sum of squares & df & Mean square & F-value & p-value & \\
\hline Model & 16771.57 & 3 & 5590.52 & 171.37 & $<0.0001$ & Significant \\
\hline A-Epoxy resin & 13081.63 & 1 & 13081.63 & 401.00 & $<0.0001$ & \\
\hline B-cockle shells powder & 334.15 & 1 & 334.15 & 10.24 & 0.0038 & \\
\hline C-Glass powder & 7.40 & 1 & 7.40 & 0.2268 & 0.6382 & \\
\hline Residual & 782.94 & 24 & 32.62 & & & \\
\hline Lack of fit & 782.94 & 23 & 34.04 & & & \\
\hline Pure error & 0.0000 & 1 & 0.0000 & & & \\
\hline Total & 17554.51 & 27 & & & & \\
\hline
\end{tabular}

A statistical test was run on the regression model and individual model variables to determine the effect of epoxy resin, cockle shells powder and glass powder on the compressive strength of concrete. Table 8 shows the ANOVA for the data yielded by Eq. (4) for compressive strength of concrete under the effect of epoxy resin, cockle shells powder, and glass powder. The model F-value of 171.37 and P-value of 0.0001 in this study showed that the model was significant. All linear terms had significant effects on the compressive strength of concrete. 


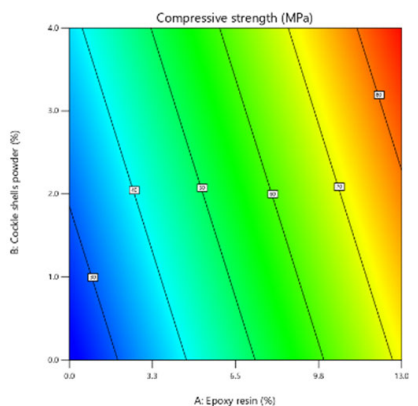

(a) Contour plot

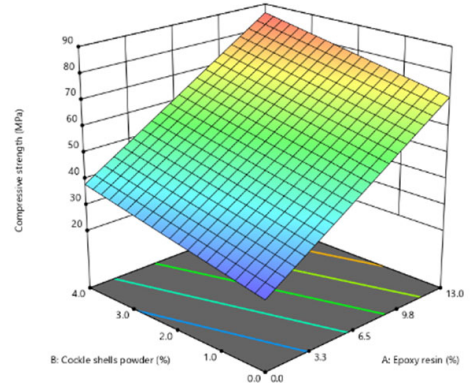

(b) 3-D response surface plot

Fig. 9. Contour plot and response surface plot of concrete compressive strength under the effect of epoxy resin, cockle shells powder and glass powder

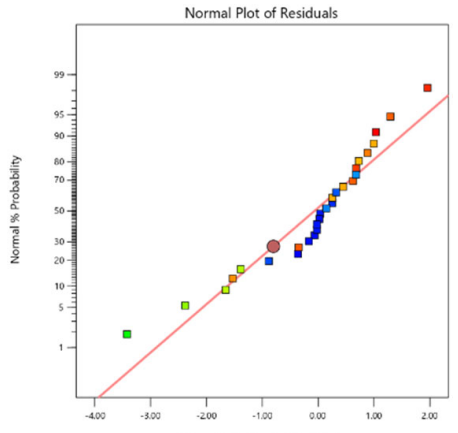

(a) Normal probability plot

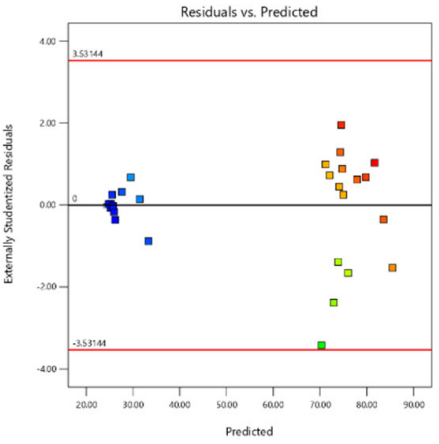

(b) Residual vs predicted (fits) plot

Fig. 10. Diagnostic plots for compressive strength of concrete under the effect of epoxy resin, cockle shells powder and glass powder

Table 9. Report of diagnostic case for compressive strength of concrete under the effect of epoxy resin, cockle shells powder and glass powder

\begin{tabular}{|c|c|c|c|c|c|c|c|c|c|}
\hline $\begin{array}{l}\text { Run } \\
\text { Order }\end{array}$ & $\begin{array}{l}\text { Actual } \\
\text { Value }\end{array}$ & $\begin{array}{l}\text { Predicted } \\
\text { Value }\end{array}$ & Residual & Leverage & $\begin{array}{l}\text { Internally } \\
\text { Studentized } \\
\text { Residuals }\end{array}$ & $\begin{array}{l}\text { Externally } \\
\text { Studentized } \\
\text { Residuals }\end{array}$ & $\begin{array}{l}\text { Cook's } \\
\text { Distance }\end{array}$ & $\begin{array}{c}\text { Influence } \\
\text { on Fitted } \\
\text { Value } \\
\text { DFFITS }\end{array}$ & $\begin{array}{c}\text { Standard } \\
\text { Order }\end{array}$ \\
\hline 1 & 24.84 & 25.19 & -0.3485 & 0.137 & -0.066 & -0.064 & 0.000 & -0.026 & 1 \\
\hline 2 & 25.49 & 25.29 & 0.1995 & 0.121 & 0.037 & 0.036 & 0.000 & 0.014 & 2 \\
\hline 3 & 26.91 & 25.51 & 1.40 & 0.099 & 0.258 & 0.253 & 0.002 & 0.084 & 3 \\
\hline 4 & 25.61 & 25.73 & -0.1194 & 0.089 & -0.022 & -0.021 & 0.000 & -0.007 & 4 \\
\hline 5 & 25.03 & 25.94 & -0.9163 & 0.092 & -0.168 & -0.165 & 0.001 & -0.052 & 5 \\
\hline 6 & 24.17 & 26.16 & -1.99 & 0.107 & -0.369 & -0.362 & 0.004 & -0.126 & 6 \\
\hline 7 & 55.94 & 70.30 & -14.36 & 0.219 & -2.845 & -3.421 & 0.568 & $-1.813^{(1)}$ & 7 \\
\hline 8 & 76.47 & 71.17 & 5.30 & 0.129 & 0.995 & 0.995 & 0.037 & 0.383 & 8 \\
\hline 9 & 75.68 & 72.03 & 3.65 & 0.241 & 0.734 & 0.727 & 0.043 & 0.410 & 9 \\
\hline 10 & 64.61 & 72.90 & -8.29 & $0.556^{(2)}$ & -2.178 & -2.380 & $1.485^{(1)}$ & $-2.663^{(1)}$ & 10 \\
\hline 11 & 67.26 & 75.99 & -8.73 & 0.087 & -1.599 & -1.656 & 0.061 & -0.510 & 11 \\
\hline 12 & 81.33 & 77.88 & 3.45 & 0.086 & 0.632 & 0.623 & 0.009 & 0.191 & 12 \\
\hline 13 & 83.49 & 79.78 & 3.71 & 0.106 & 0.688 & 0.680 & 0.014 & 0.234 & 13 \\
\hline 14 & 87.11 & 81.67 & 5.44 & 0.148 & 1.032 & 1.033 & 0.046 & 0.430 & 14 \\
\hline 15 & 81.76 & 83.57 & -1.81 & 0.211 & -0.357 & -0.350 & 0.009 & -0.181 & 15 \\
\hline 16 & 78.33 & 85.47 & -7.14 & $0.296^{(2)}$ & -1.489 & -1.530 & 0.233 & -0.992 & 16 \\
\hline 17 & 66.71 & 73.88 & -7.17 & 0.148 & -1.360 & -1.386 & 0.080 & -0.578 & 17 \\
\hline 18 & 76.55 & 74.09 & 2.46 & 0.109 & 0.456 & 0.448 & 0.006 & 0.157 & 18 \\
\hline 19 & 81.28 & 74.31 & 6.97 & 0.083 & 1.275 & 1.293 & 0.037 & 0.390 & 19 \\
\hline 20 & 84.72 & 74.52 & 10.19 & 0.070 & 1.851 & 1.957 & 0.064 & 0.537 & 20 \\
\hline 21 & 79.63 & 74.74 & 4.89 & 0.069 & 0.888 & 0.884 & 0.015 & 0.241 & 21 \\
\hline 22 & 76.37 & 74.96 & 1.42 & 0.081 & 0.259 & 0.254 & 0.001 & 0.075 & 22 \\
\hline 23 & 24.91 & 24.78 & 0.1292 & 0.099 & 0.024 & 0.023 & 0.000 & 0.008 & 23 \\
\hline 24 & 25.61 & 25.73 & -0.1194 & 0.089 & -0.022 & -0.021 & 0.000 & -0.007 & 24 \\
\hline 25 & 29.42 & 27.62 & 1.80 & 0.084 & 0.329 & 0.323 & 0.002 & 0.098 & 25 \\
\hline 26 & 33.23 & 29.52 & 3.71 & 0.101 & 0.686 & 0.678 & 0.013 & 0.228 & 26 \\
\hline 27 & 32.20 & 31.41 & 0.7868 & 0.140 & 0.149 & 0.145 & 0.001 & 0.059 & 27 \\
\hline 28 & 28.78 & 33.31 & -4.53 & 0.199 & -0.887 & -0.882 & 0.049 & -0.440 & 28 \\
\hline
\end{tabular}

(1) Exceeds limits.

(2) Observation with leverage $>2.00 \times$ (average leverage). 
ANOVA was used to determine the model's satisfactoriness for compressive strength of concrete under the effect of epoxy resin, cockle shells powder and glass powder. $\mathrm{R}^{2}$ and adjusted $\mathrm{R}^{2}$ values of 0.99554 and 0.9498 indicate strong relativity of experimental findings with the fitted regression model. The high value of adjusted $\mathrm{R}^{2}$ showed a reasonable agreement between the observed and predicted values of the compressive strength of concrete and suggested that the proposed linear model equation offers satisfactory and accurate results. The lack of fit is also insignificant for compressive strength of concrete under the effect of epoxy resin, cockle shells powder and glass powder, which is expected because an appropriate model is required. The distribution of points compatible with the regression line demonstrates the applied regression model's increased adequacy. Also, random bouncing of residuals presents that the implied relationship is good. Simultaneously, the model's low coefficient of variance (10.36\%) suggested a high degree of accuracy and a high degree of dependability for the observed data. Hence, the generated model was satisfactory for estimating the compressive strength of concrete in the range of experimental variables under the effect of epoxy resin, cockle shells powder, and glass powder.

\subsection{Optimization of compressive strength of some combination mix aggregate of concrete}

The desirability close to one is the most desirable because it increasingly shows the value of optimization accuracy. The desirability is to indicate the level of fulfillment of the specified criteria. The prediction of optimal conditions in the cement mixing process between the epoxy resin and cockle shells powder (Fig. $11 \mathrm{a}$ ) is $4.88 \%, 4.0 \%$, respectively, with the desirability of 0.672 . The most optimal formula solutions in the cement mixing process between the epoxy resin and glass powder are $6.85 \%, 8.0 \%$, or equivalent to the desirability of $56.2 \%$ (Fig. 11b). Optimal conditions in the cement mixing process between cockle shells powder and glass powder (Fig. 11c) are $4.0 \%, 8.0 \%$, respectively, with the desirability of 1.0 . The optimal formulation in the cement mixing process between epoxy resin, cockle shells powder, and glass powder is $4.40 \%, 4.0,8.0 \%$, respectively, equivalent to the desirability of $76.1 \%$ (Fig. 11d). Under these conditions, the mixing components will produce cement with compressive strength in each formulation of 54.71 MPa, 47.82 MPa, 147.0 MPa, and 56.08 MPa. These results are in line with the research of Murugan et al. (2020), who reported that cockle shell substitution (5 - 30\%) would provide compressive strength in concrete in the range of $42.46 \mathrm{MPa}$ to $52.64 \mathrm{MPa}$. The formulations in each of these can be used according to the availability of raw materials for cockle shells waste and glass waste and the level of compressive strength required by the user.

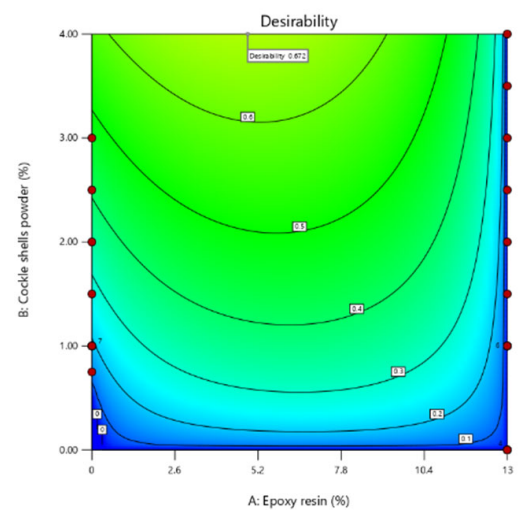

(a) Mix of epoxy resin with cokcle sheel powder

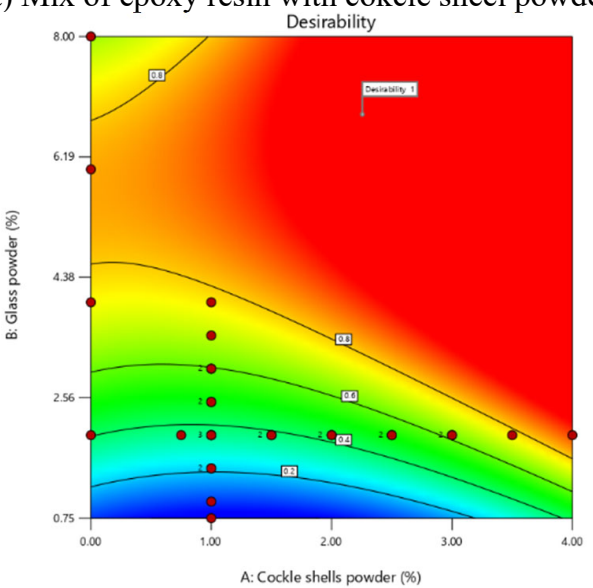

(c) Mix of cokcle sheel powder with glass powder

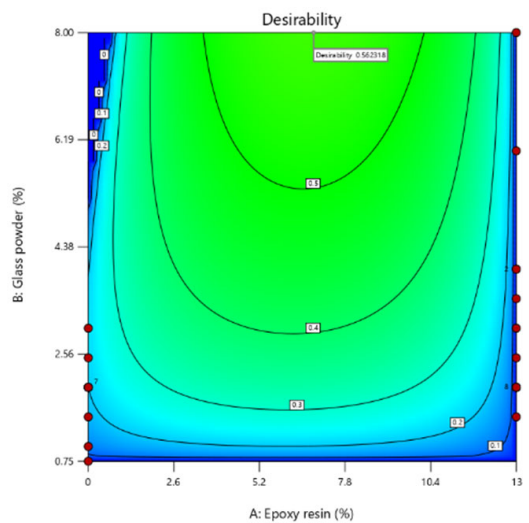

(b) Mix of epoxy resin with glass powder

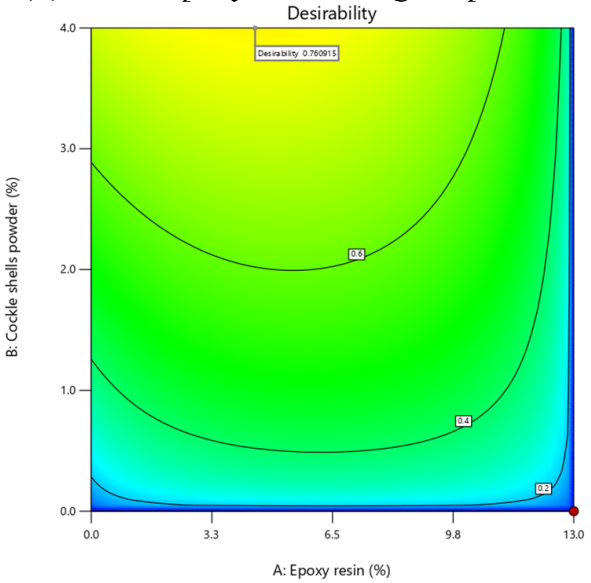

(d) Mix of epoxy resin, cokcle sheel powder and glass powder

Fig. 11. Optimization of epoxy resin, cockle shell powder, and glass powder using desirability analysis 


\section{Conclusion}

In this study, the compressive strength of mixed concrete aggregates was optimized from waste cockle shells and waste glass. The compressive strength of concrete incorporated with epoxy resin, cockle shells powder, and glass powder is identified to be higher than that of normal concrete. It is appropriate to evaluate such sustainable buildings based on the findings. The linear and quadratic polynomial models utilized in this study demonstrated that they could accurately predict compressive strength responses. It was found that $4.88 \%$ epoxy resin and $4.0 \%$ cockle shells powder improved the compressive strength at two types of combination aggregate. Another type of concrete mix aggregate, $6.85 \%$ epoxy resin and $8.0 \%$ glass powder improved the compressive strength. Concrete mix aggregate with cockle shells powder and glass powder respectively at $4.0 \%$ and $8.0 \%$ provides optimization of compressive strength. Finally, the combination of epoxy resin, cockle shells powder, and glass powder of $4.40 \%, 4.0,8.0 \%$, respectively, will also optimize the compressive strength of the concrete. In addition, only mixing of $4.0 \%$ cockle shells powder and $8.0 \%$ glass were noticed to yield maximum compressive strength on concrete. Optimized values are a good way to build with waste material in a way that is environmentally friendly. RSM was discovered to provide a substantial quantity of information in a short time and with the fewest possible experiments.

\section{References}

Basri, H., Mannan, M., \& Zain, M. F. M. (1999). Concrete using waste oil palm shells as aggregate. Cement and concrete Research, 29(4), 619-622.

Ede, A. N., Gideon, P. O., Akpabot, A. I., Oyebisi, S. O., Olofinnade, O. M., \& Nduka, D. O. (2021). Review of the Properties of Lightweight Aggregate Concrete Produced from Recycled Plastic Waste and Periwinkle Shells. Paper presented at the Key Engineering Materials.

Gupta, A., Gupta, N., Shukla, A., Goyal, R., \& Kumar, S. (2020). Utilization of recycled aggregate, plastic, glass waste and coconut shells in concrete-A review. Paper presented at the IOP Conference Series: Materials Science and Engineering.

Habibi, A., Ramezanianpour, A. M., Mahdikhani, M., \& Bamshad, O. (2021). RSM-based evaluation of mechanical and durability properties of recycled aggregate concrete containing GGBFS and silica fume. Construction and Building Materials, $270,121431$.

Hammoudi, A., Moussaceb, K., Belebchouche, C., \& Dahmoune, F. (2019). Comparison of artificial neural network (ANN) and response surface methodology (RSM) prediction in compressive strength of recycled concrete aggregates. Construction and Building Materials, 209, 425-436.

Hamouda, H. I., Nassar, H. N., Madian, H. R., Amr, S. S. A., \& El-Gendy, N. S. (2015). Response surface optimization of bioethanol production from sugarcane molasses by Pichia veronae strain HSC-22. Biotechnology research international, 2015.

Hilal, N. N., Sahab, M. F., \& Ali, T. K. M. (2021). Fresh and hardened properties of lightweight self-compacting concrete containing walnut shells as coarse aggregate. Journal of King Saud University-Engineering Sciences, 33(5), 364-372.

Jayanti, D. S., Amrida, N., Sitorus, A., \& Thamren, D. S. (2021). Potential Hydroelectric Power Plant for a Remote Area Utilizing Subwatershed Lawe-Simpali. Mathematical Modelling of Engineering Problems, 8(5), 715-720. doi:10.18280/mmep.080505

Karri, R. R., Ravindran, G., \& Paramasivan, B. (2021). Predictive capability evaluation and optimization of sustainable biodiesel production from oleaginous biomass grown on pulp and paper industrial wastewater. Renewable Energy, 168, $204-215$.

Mohamad, N., Muthusamy, K., \& Ismail, M. A. K. E. G. (2021). Cockle Shell as Mixing Ingredient in Concrete: A Review. CONSTRUCTION, 1(2), 9-20.

Murugan, S., Natarajan, M., Karthik, V., \& Johnpaul, V. (2020). Utilization of cockle shell aggregates in the production of ecoconcrete. Materials Today: Proceedings.

Nematzadeh, M., Shahmansouri, A. A., \& Fakoor, M. (2020). Post-fire compressive strength of recycled PET aggregate concrete reinforced with steel fibers: Optimization and prediction via RSM and GEP. Construction and Building Materials, 252, 119057.

Raseela, M., \& George, B. M. S. (2019). Experimental investigation on use of cockle shell as partial coarse aggregate replacement in concrete. Concrete, International, 4(2), 504-510.

Ren, B., Chen, C., Li, C., Fu, X., You, L., \& Liu, R. H. (2017). Optimization of microwave-assisted extraction of Sargassum thunbergii polysaccharides and its antioxidant and hypoglycemic activities. Carbohydrate Polymers, 173, $192-201$.

Salarian, A.-A., Hami, Z., Mirzaei, N., Mohseni, S. M., Asadi, A., Bahrami, H., Vosoughi, M., Alinejad, A., \& Zare, M.-R. (2016). $\mathrm{N}$-doped $\mathrm{TiO} 2$ nanosheets for photocatalytic degradation and mineralization of diazinon under simulated solar irradiation: Optimization and modeling using a response surface methodology. Journal of Molecular Liquids, 220, 183-191.

Sinkhonde, D., Onchiri, R. O., Oyawa, W. O., \& Mwero, J. N. (2021). Response surface methodology-based optimisation of cost and compressive strength of rubberised concrete incorporating burnt clay brick powder. Heliyon, 7(12), e08565. doi:https://doi.org/10.1016/j.heliyon.2021.e08565

Sitorus, A., Fauzi, A., Ramadhan, G., Hasan, A. R., \& Karyadi, A. (2018). Conceptual Design of Harvesters Knife for Chinese Spinach (Ipomoea Reptans Poir.): CAD Approach. Paper presented at the 2018 International Conference on Computing, Engineering, and Design (ICCED).

Yirgu, Z., Leta, S., Hussen, A., Khan, M. M., \& Aragaw, T. (2021). Optimization of microwave-assisted carbohydrate extraction from indigenous Scenedesmus sp. grown in brewery effluent using response surface methodology. Heliyon, 7(5), e07115. doi:https://doi.org/10.1016/j.heliyon.2021.e07115

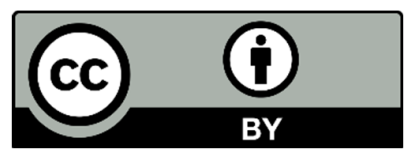

(C) 2022 by the authors; licensee Growing Science, Canada. This is an open access article distributed under the terms and conditions of the Creative Commons Attribution (CC-BY) license (http://creativecommons.org/licenses/by/4.0/). 